\title{
More Numerical Results on Red Blood Cell Geometry
}

\author{
H. Westcott VAYo and Masanori K. Shibata* \\ Department of Mathematics, University of Toledo, \\ Toledo, Ohio, U.S.A.
}

\begin{abstract}
Summary The length of arc or circumference for the cross-section of the red blood cell has been determined for the normal range of dimensional values for mammalian red cells. Graphs for arc length vs. diameter and vs. cross-sectional area, for fixed thickness, are included. The graphs give an indication of the rates of change of the geometrical parameters contained therein. A special case of Fick's Law, based on the model geometry utilizing the Oval of Cassini, is presented for the mammalian red cell. The ratios of surface area to volume necessary for a complete Fick's Law formulation, are given for the normal range of dimensional values for the mammalian red cell.
\end{abstract}

Key Words: erythrocyte, Fick's Law, RBC geometry.

In an earlier paper (VAYO and SHiBaTA, 1982) we confirmed the correctness of Funaki's formulas for cross-sectional area, surface area, and volume based on the Oval of Cassini. These formulas can be written, save for the volume formula, in terms of elliptic integrals (VAYO, 1983). This allows for a more economical notation and easier manipulation when these are needed for studies in mechanics, gas exchange, etc.

The arc length or circumference of the red blood cell, based on the Oval of Cassini, is found in GreEnHILL (1892) and in MATZ (1895) as follows:

where

$$
C=\frac{4 c^{2}}{\left(c^{2}+a^{2}\right)^{1 / 2}} \int_{0}^{\pi / 2} \frac{\mathrm{d} \phi}{\left(1-\alpha^{2} \sin ^{2} \phi\right)^{1 / 4}},
$$

$$
\alpha^{2}=\frac{4 a^{2} c^{2}}{\left(c^{2}+a^{2}\right)^{2}}
$$

The parameters $a$ and $c$ are the same as given in VAYO and SHIBATA (1982). This circumference formula is found in terms of elliptic integrals in VAYO (1983).

Received for publication October 12, 1983

* Present address: Junior College of Tokai University, Tokyo, 108 Japan

柴田正憲 
Table 1.

\begin{tabular}{|c|c|c|c|c|c|c|c|c|c|}
\hline Diameter $d(\mu \mathrm{m})$ & \multicolumn{3}{|c|}{7.0} & \multicolumn{3}{|c|}{7.1} & \multicolumn{3}{|c|}{7.2} \\
\hline Least thickness $t(\mu \mathrm{m})$ & 0.8 & 0.9 & 1.0 & 0.8 & 0.9 & 1.0 & 0.8 & 0.9 & 1.0 \\
\hline Arc length $C(\mu \mathrm{m})$ & 17.62 & 17.56 & 17.51 & 17.88 & 17.82 & 17.76 & 18.14 & 18.07 & 18.02 \\
\hline$A / V\left(\mu \mathrm{m}^{-1}\right)$ & 1.41 & 1.40 & 1.39 & 1.39 & 1.38 & 1.37 & 1.37 & 1.36 & 1.35 \\
\hline Diameter $d(\mu \mathrm{m})$ & & 7.3 & & & 7.4 & & & 7.5 & \\
\hline Least thickness $t(\mu \mathrm{m})$ & 0.8 & 0.9 & 1.0 & 0.8 & 0.9 & 1.0 & 0.8 & 0.9 & 1.0 \\
\hline Arc length $C(\mu \mathrm{m})$ & 18.40 & 18.34 & 18.28 & 18.66 & 18.60 & 18.54 & 18.92 & 18.86 & 18.80 \\
\hline$A / V\left(\mu \mathrm{m}^{-1}\right)$ & 1.35 & 1.34 & 1.33 & 1.34 & 1.33 & 1.32 & 1.32 & 1.31 & 1.30 \\
\hline Diameter $d(\mu \mathrm{m})$ & & 7.6 & & & 7.7 & & & 7.8 & \\
\hline Least thickness $t(\mu \mathrm{m})$ & 0.8 & 0.9 & 1.0 & 0.8 & 0.9 & 1.0 & 0.8 & 0.9 & 1.0 \\
\hline Arc length $C(\mu \mathrm{m})$ & 19.18 & 19.11 & 19.06 & 19.44 & 19.37 & 19.31 & 19.70 & 19.63 & 19.57 \\
\hline$A / V\left(\mu \mathrm{m}^{-1}\right)$ & 1.30 & 1.29 & 1.29 & 1.29 & 1.28 & 1.27 & 1.27 & 1.26 & 1.25 \\
\hline Diameter $d(\mu \mathrm{m})$ & & 7.9 & & & 8.0 & & & & \\
\hline Least thickness $t(\mu \mathrm{m})$ & 0.8 & 0.9 & 1.0 & 0.8 & 0.9 & 1.0 & & & \\
\hline Arc length $C(\mu \mathrm{m})$ & 19.96 & 19.89 & 19.83 & 20.22 & 20.15 & 20.10 & & & \\
\hline$A / V\left(\mu \mathrm{m}^{-1}\right)$ & 1.26 & 1.25 & 1.24 & 1.24 & 1.23 & 1.22 & & & \\
\hline
\end{tabular}

Table 1 contains numerical values for the circumference for the same values of diameter and least thickness as used in our earlier paper (VAyo and SHibata, 1982).

It is also of interest to graphically observe the relationships between several of the dimensional parameters when we fix the thickness $t$. The reason the thickness was fixed rather than the diameter $d$ is that there are fewer values for thickness with which to make a meaningful graph. We show typical graphs in Fig. 1 for circumference $v s$. diameter (and $v s$. cross-sectional area). The graphs appear to be linear; we have fit a straight line to the graphs in Fig. 1 and also to the surface area $v s$. diameter (and $v s$. volume) data by using a least squares approximation. As expected, the results are very accurate and are given by the following equations (for $t=0.8 \mu \mathrm{m}$ ):

$\begin{array}{ll}\text { Surface area-Diameter } & Y=33.2 X-124 \\ \text { Surface area-Volume } & Y=0.891 X+40.2 \\ \text { Circumference-Diameter } & Y=2.60 X-0.580 \\ \text { Circumference-Cross-sectional area } & Y=0.685 X+8.62\end{array}$

These least-squares lines are in slope-intercept form and they give the rate of change of the vertical axis variable $(Y)$ with respect to the horizontal axis variable $(X)$ as well as the value of the vertical axis variable for the minimum value of the horizontal axis variable. If the slopes of these lines are constant, as they appear to be, the interpretation would be that the changes in vertical and horizontal axis variables are in the same ratio for the entire range of diameter values 

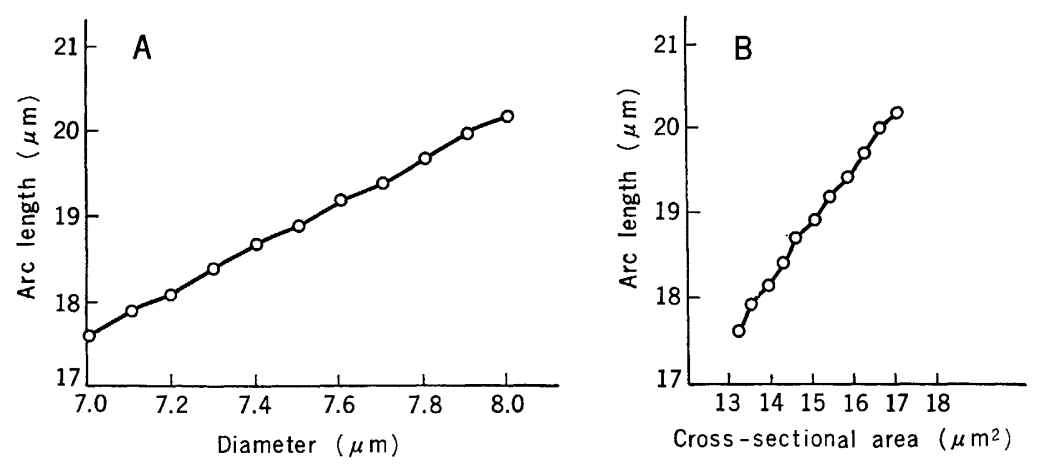

Fig. 1. Graphs of circumference (arc length) vs. diameter and circumference vs. crosssectional area for a model red cell of least thickness $0.8 \mu \mathrm{m}$.

(for fixed least thickness).

The main parameter of interest in the least squares approximations was the slope.

If a cell of constant volume is suspended in a homogeneous liquid which contains a solute of concentration $c_{0}$, we have a known method to find the concentration $c(t)$ of solute inside the cell for any time. This is known as Fick's Law (DAvson and DANiELli, 1970) and can be written thusly

$$
\frac{\mathrm{d} c}{\mathrm{~d} t}=\frac{k A}{V}\left(c_{0}-c(t)\right)
$$

where $A$ is the surface area of the cell, $V$ the volume of the cell, and $k$ the permeability constant for the cell membrane for a particular solute. The red blood cell membrane permits solute exchange and thus would satisfy Fick's Law under the assumption that the solute is homogeneously distributed in the plasma. The set of geometric values of surface area and volume, based on the Oval of Cassini model of the red cell, provided in our earlier paper (VAYo and SHIBATA, 1982) may be used for the constants $A$ and $V$ in Eq. (3). This would provide a specific Fick's Law for each of the sizes of red blood cell tabulated earlier; if the permeability constant $k$ for a specific solute is also known, then Fick's Law may be further specialized for each solute. To this end, we have included in Table 1 values for the ratio $A / V$ for the cells of diameter $d$ and least thickness $t$. Thus a very specific law may be utilized by investigators for a particular solute and cell size.

Equation (3) can be solved for the concentration $c(t)$ if we use the initial condition $c(0)=0$. The solution is given as

$$
c(t)=c_{0}\left\{1-\exp \left(-\frac{k A}{V} t\right)\right\} .
$$

An important point is to be observed here if we write the solution in the form

Vol. 34, No. 2, 1984 


$$
\frac{c_{0}-c}{c_{0}}=\mathrm{e}^{-k(A / V) t} .
$$

If we make a graph of $\ln \left\{\left(c_{0}-c\right) / c_{0}\right\}$ vs. $t$ we will obtain a straight line with slope $-k A / V$; thus if we know $A / V$, we could obtain $k$ from those experimental values used in the graph. Note that in Eq. (5) if $c<c_{0}$ then solute will flow (diffuse) into the red cell interior, hence $k$ will be a positive constant determined by the structure and thickness of the membrane. On the other hand, if $c>c_{0}$ then solute moves from red cell interior to the plasma surrounding it. The dependence of the rate of concentration change on the value of $A / V$ is very evident here and further reinforces the need for an accurate geometric model for the red blood cell. Our hope is that these results will be useful to those involved in red cell physiology.

The authors would like to thank Barbara Bowman for assistance in manuscript preparation and the editor for several helpful suggestions.

\section{REFERENCES}

Davson, H. and Danielli, J. F. (1970) The Permeability of Natural Membranes, Hafner Publ. Co., Darien, Conn., pp. 38-47.

Greenhill, A. G. (1892) The Application of Elliptic Functions, Macmillan Publ. Co., New York, pp. 164-165.

Matz, F. P. (1895) The rectification of the Cassinian Oval by means of elliptic functions. $A m$. Math. Monthly, 2: 221-222.

VAyo, H. W. (1983) Some red blood cell geometry. Can. J. Physiol. Pharm., 61: 646-649.

Vayo, H. W. and Shibata, M. K. (1982) Numerical results on red blood cell geometry. Jpn. J. Physiol., 32, 891-894. 